\section{High Tunnel Tree Fruit Production: The Final Frontier?}

\author{
Gregory A. Lang ${ }^{1}$
}

Additional Index words. Prunus avium, sweet cherry, dwarfing rootstocks, protected agriculture, environmental modification, multi-bay tunnels

SuMMARY. High tunnel production systems typically use horticultural crops that are annually or biennially herbaceous, high in value, short in stature, and quick to produce. At best, tree fruits may fit only one of these criteria-high value. Sweet cherry (Prunus avium) may command high enough values in premium market niches to make high tunnel production strategies worth attempting. Furthermore, sweet cherry production can be a risky endeavor, even in optimal climates, due to the potentially devastating effects of preharvest rain that cause fruit cracking. Consequently, environmental modification by tunnels in regions like the Great Lakes provides a significant risk reduction. Additional potential benefits, such as protection from frosts, diseases, insects, wind scarring, etc., add further production value. Multi-bay high tunnels were constructed in 2005 at two Michigan State University experiment stations, over established and newly planted sweet cherry trees on dwarfing rootstocks, to study and optimize the effects of production environment modification on vegetative and reproductive growth, marketing season extension, and protection of cherries from diseases, insect pests, and/or physiological disorders. Results with tunnels thus far include premium fruit quality and high crop value; increased leaf size and terminal shoot growth; decreased radial trunk growth; decreased chemical pesticide inputs; decreased incidence of cherry leaf spot (Blumeriella jaapii) and bacterial canker (Pseudomonas syringae); increased incidence of powdery mildew (Podosphaera clandestina); inconclusive effects on brown rot (Monolinia fructicola); no or reduced infestation by plum curculio (Conotrachelus nenuphar) or cherry fruit fly (Rbagoletis cingulata); dramatically reduced japanese beetle (Popillia japonica) damage; and increased black cherry aphid (Myzus cerasi) and two-spotted spider mite (Tetranychus urticae) populations.

$\mathrm{H}$ igh tunnel production of fruit crops requires a high potential market value to justify the added expense of the tunnel structure to orchard management costs. Fruit production in high tunnels has focused largely on nonwoody perennial or biennial berry crops such as strawberry (Fragaria Xananassa) and raspberry (Rubus idaeus) (Lamont et al., 2003). These crops are similar to the high-value vegetable and cut flower crops that have been successful in high tunnels (Lamont and Orzolek, 2003). Apple (Malus $\times$ domestica) trees on dwarfing rootstocks are suitably small statured for containment within a high tunnel structure, but most cultivars may

Department of Horticulture, Michigan State University, East Lansing, MI 48824

The high tunnel research reported here was funded in part by grants from Project GREEEN, by the International Fruit Tree Association, and by the Michigan Agricultural Experiment Station, as well as in-kind donations from Haygrove Tunnels, International Plant Management, and Gisela Inc. The research project assistance of Bill Shane, Phil Schwallier, Eric Hanson, Rufus Isaacs, Greg Vlaming, and Tara Valentino is gratefully acknowledged.

${ }^{1}$ Corresponding author. E-mail: langg@msu.edu. command insufficient market returns to make high tunnel production economically feasible. In North America, as elsewhere in the world, the market returns for fresh sweet cherry fruit have been remarkably strong and relatively consistent since the mid1990s (O'Rourke, 2006). This strong market performance is, to some extent, due to the high desirability of the fruit to consumers, its limited seasonal appearance in the marketplace, and the fact that sweet cherry is among the riskiest fruit crops to grow. Competing for, and retaining, shelf space in retail produce markets requires a consistent supply and consistently high quality. Sweet cherry trees are highly susceptible to numerous potential production limitations such as fruit damage or even tree death from low temperatures, insect and disease pests, and in particular, raininduced fruit cracking during the final stages of fruit ripening (Webster and Looney, 1996).

Therefore, sweet cherry is an obvious market-driven candidate fruit for potential adaptation to high tunnel production strategies in areas where these production risks are significant. Yet, the woody perennial structure of the sweet cherry and its inherent reproductive and vegetative physiology present perhaps a "final frontier" for crop adaptation to tunnels. Challenging evolutionary traits include potential tree size (in nature, sweet cherry is a tall forest tree) and the fact that a high percentage of fruit-bearing sites in the tree require about 16 to 26 months from initiation of shoot growth to the harvest of the first fruit borne on spurs on that shoot. Consequently, rootstocks that are dwarfing and precocious, coupled with high-density orchard training systems (Lang, 2000), are likely to be critical to achieve the reduction in tree stature suitable for containment within tunnel structures and early, high fruit production for repayment of substantial establishment costs.

The majority of fresh market sweet cherry production in North America is located in the low-rainfall regions of the western United States and British Columbia. Sweet cherry production also is significant, although at a much reduced scale, in the Great Lakes region (especially Michigan, Ontario, and New York). The urban and suburban population centers of the midwestern and Atlantic states and provinces provide major

\begin{tabular}{llll}
\hline $\begin{array}{l}\text { Units } \\
\begin{array}{l}\text { To convert U.S. to SI, } \\
\text { multiply by }\end{array}\end{array}$ & U.S. unit & SI unit & $\begin{array}{l}\text { To convert SI to U.S., } \\
\text { multiply by }\end{array}$ \\
\hline 0.4047 & acre $(\mathrm{s})$ & $\mathrm{ha}$ & $2.471 \mathrm{l}$ \\
0.3048 & $\mathrm{ft}$ & $\mathrm{m}$ & 3.2808 \\
2.54 & inch $(\mathrm{es})$ & $\mathrm{cm}$ & 0.3937 \\
25.4 & inch $(\mathrm{es})$ & $\mathrm{mm}$ & 0.0394 \\
0.4536 & $\mathrm{lb}$ & $\mathrm{kg}$ & 2.2046 \\
0.0254 & $\mathrm{mil}$ & $\mathrm{mm}$ & 39.3701 \\
0.4470 & $\mathrm{mph}$ & $\mathrm{m} \cdot \mathrm{s}^{-1}$ & 2.2369 \\
28.3495 & $\mathrm{oz}$ & $\mathrm{g}$ & 0.0353 \\
2.2417 & ton $/ \mathrm{acre}$ & $\mathrm{t} \cdot \mathrm{ha}^{-1}$ & 0.4461 \\
$\left({ }^{\circ} \mathrm{F}-32\right) \div 1.8$ & ${ }^{\circ} \mathrm{F}$ & ${ }^{\circ} \mathrm{C}$ & $\left(1.8 \times{ }^{\circ} \mathrm{C}\right)+32$ \\
& & &
\end{tabular}


markets not only for standard (high volume, moderately priced) sweet cherry retail sales (as currently supplied by western producers), but also higher margin farm market and pickyour-own sales as well as upscale retail markets whose customers will pay a premium for locally grown and/or organic, high-quality produce. These latter markets must be targeted to make the economics of high-tunnel sweet cherry production viable.

\section{Michigan State University's high tunnel cherry research}

Various orchard-covering strategies have been attempted over the years and around the world to protect sweet cherry fruit from rain during harvest (e.g., Meland, 2005; Pennell and Webster, 1996). These have included single-row "tent" plastic covers achieved via various designs, from three wires and wooden posts to steel supporting arches and rails, as well as multiple rowcovering systems ranging from high tunnels to bona fide greenhouses. The multitude of designs ranges from inexpensive and retractable to quite expensive and permanent. While cost is a factor for all growers, additional preferences or requirements that may be site specific also have played a role in the development of many of these strategies (e.g., typically mild versus torrential rain events, severity of winds, existing orchards of large trees versus new high-density orchards of smaller trees, target markets, additional uses for bird protection, complementary greenhouse operations already established, etc.).

In the late 1990s, cherry growers in the United Kingdom began adapting multi-bay high tunnels to sweet cherry orchards, following the successful reversal of declining U.K. strawberry culture by improving the production environment under tunnels (G. Moore, personal communication). Multi-bay high tunnels generally are used seasonally for protected crop production rather than year-round like some single-bay, stand-alone high tunnels (which often are managed and used similarly to greenhouses). Multiversus single-bay tunnel differences include less load-bearing structural strength resulting from increased distances between structural steel supports, covering with a single layer of plastic that is removed before winter or earlier, and sides that usually are open.
Consequently, multi-bay high tunnels cost less to establish than do single-bay tunnels, but they cannot withstand snow loads in winter, they tend to be more susceptible to high winds, and they usually are vented manually by simply pushing the lowest portion of the plastic cover $1 \mathrm{~m}$ or more up and down the sides of the tunnel arch span, as needed. The first use of high tunnels for cherry production in the United States probably occurred at Weaver Orchards in Pennsylvania in 2003 (Weaver and Weaver, 2003). In addition to protection from rain-induced fruit cracking during the ripening period, protection from spring frosts, rain-disseminated diseases, and fruit damage from wind or pests [e.g., insects, birds, deer (e.g., Odocoileus spp.)] also would be of interest. Additionally, the potential exists to manipulate or extend the period of fruit ripening, and to more rapidly develop an extensive tree canopy to hasten orchard establishment and initial production. Thus, multi-bay high tunnels may provide a suitable, moderate cost compromise compared with pole and wire single-row protection (cheaper, primarily for rain exclusion) and complete single bay or greenhouse multirow protection (expensive, better control of rain and wind and low temperatures, but difficult to control high summer temperatures and humidity).

In 2004, a comprehensive high tunnel research trial was initiated at Michigan State University (MSU) which resulted in the 2005 establishment of three $50 \mathrm{~m}$ long $\times 28 \mathrm{ft}$ wide multi-bay high tunnels (Haygrove, Lancaster, PA) at the MSU Clarksville Horticultural Experiment Station (CHES) and eight $62 \mathrm{~m}$ long $\times 24 \mathrm{ft}$ wide multibay high tunnels at the MSU Southwest Michigan Research and Extension Center (SWMREC) near Benton Harbor. A review of climatic data (Michigan State University, 2005a, 2005b) from 2000 to 2005 during the cherry ripening period at CHES and SWMREC evaluated the number of days with potentially damaging rain events (i.e., $>10 \mathrm{~mm}$ ) during each $10-\mathrm{d}$ interval in June and July. At CHES, in 4 of 6 years, at least one damaging rain event occurred during each $10-\mathrm{d}$ period from the beginning of June through 10 July. At SWMREC, at least one damaging rain event occurred during each of the first $10 \mathrm{~d}$ of June and July in 5 of 6 years; incidents were somewhat less frequent from 10 to 30 June. Consequently, it would be expected that simply covering sweet cherry trees in June and July with high tunnels would reduce the incidence of rain-induced fruit cracking at both sites in 4 or 5 years of every 6 years. The extent of actual crop damage would vary from year to year, depending on the exact stage of fruit development as well as the timing of rainfall and other accompanying climatic conditions such as wind, relative humidity, etc.

The CHES tunnels were erected over existing 'Rainier', 'Lapins', and 'Sweetheart' sweet cherry trees that had been planted in 2000 on 'Gisela ${ }^{\circledR}$ 5' ('Gi 5') and 'Gi 6' rootstocks. The SWMREC tunnels were erected over open ground and four were planted to a wide assortment of sweet cherry cultivars (Table 1) on 'Gi 5', 'Gi 6', and ' $\mathrm{Gi} 12$ ' rootstocks, with 'Rainier', 'Skeena', and 'Early Robin' as the main replicated data cultivars and 35 additional genotypes (both cultivars and elite breeding selections), including two sour or "sweet-tart" ( $P$. cerasus) cultivars, as guard trees. Duplicate plots without tunnels ("unprotected") were established for nonstatistical comparisons. The plastic used to cover the tunnels was a 6-mil polyethylene (Luminance THB; British Polythene Industries, London) that is reported to transmit $88 \%$ and $43 \%$ of the photosynthetically active radiation $(P A R)$ and infrared light wavelengths, respectively, while partially screening ultraviolet (ultraviolet-A and ultraviolet-B). At CHES, the trees have had extensive annual summer and winter pruning to retrofit them to the tunnel structures. At SWMREC, the newly planted trees were grown for one season to establish a strong root system, and then various precision bud management strategies (Lang, 2005, 2007) were imposed to develop single leader vertical axe-type trees (Fig. 1).

In addition to the high tunnel systems, several orchard floor management components were studied: 1) a conventional herbicide strip in the tree row, 2) a black polypropylene weed barrier fabric (Pro-V ${ }^{\mathrm{TM}}$; DeWitt, Sikestown, MO) in the tree row and/or tractor alley, 3) a grass tractor alley, and 4) a white woven 
Table 1 . Sweet cherry and sweet-tart cherry genotypes and Gisela (Gi) rootstocks under evaluation in multi-bay high tunnel production systems and duplicate unprotected comparison plots at Michigan State University's Clarksville Horticultural Experiment Station (CHES) and Southwest Michigan Research and Extension Center (SWMREC).

\begin{tabular}{|c|c|c|}
\hline & Dwarfing (on Gi 5) & $\begin{array}{l}\text { Semi-vigorous (on } \\
\text { Gi } 6 \text { or Gi 12) }\end{array}$ \\
\hline \multicolumn{3}{|l|}{ CHES (planted 2000) } \\
\hline Primary data trees & Rainier & Rainier/Gi 6 \\
\hline Pollinizer trees & Lapins & $\begin{array}{l}\text { Lapins/Gi } 6 \\
\text { Sweetheart/Gi } 6\end{array}$ \\
\hline \multicolumn{3}{|l|}{ SWMREC (planted 2005) } \\
\hline Primary data trees & $\begin{array}{l}\text { Rainier } \\
\text { Skeena }\end{array}$ & Early Robin/Gi 12 \\
\hline Pollinizer/guard trees & $\begin{array}{l}\text { Benton } \\
\text { BlackGold } \\
\text { BlushingGold } \\
\text { Cristalina } \\
\text { Lapins } \\
\text { Regina } \\
\text { Sandra Rose } \\
\text { Sonnet } \\
\text { Summit } \\
\text { Tieton } \\
\text { Ulster }\end{array}$ & Glacier/Gi 6 \\
\hline Sweet-tart trees & Jubileum & Danube/Gi 6 \\
\hline Elite breeding selections & $\begin{array}{l}8 \text { from Cornell } \\
12 \text { from WSU }\end{array}$ & 1 from Cornell/Gi 6 \\
\hline
\end{tabular}

${ }^{2}$ Washington State University.

reflective fabric (Extenday ${ }^{\circledR}$, Auckland, New Zealand) placed in both the tree row and the tractor alley. Automated climatic monitoring equipment (Onset Computer Corp., Bourne, MA) was installed during 2006 in the middle of each tunnel and standard unprotected plot at both sites to record air temperature at canopy height, soil temperature at a depth of $10 \mathrm{~cm}$, relative humidity, wind speed, $P A R$, and leaf wetness.

Among the high tunnel orchard management and research objectives were to fill the protected orchard space and begin fruiting rapidly; to manage and harvest the trees primarily from the ground, without ladders; to achieve consistent and adequate yields of premium quality fruit with regard to size, sweetness, and appearance; to reduce fruit defects due to cracking, rots, bird damage, etc., and to examine whether the need for synthetic chemical pesticide inputs is reduced or increased.

\section{Preliminary results and observations}

Cultural conditions and VEGETATIVE GROWTH. The black weed barrier fabric effectively suppressed weeds without the use of herbicides, thereby reducing the potential presence of host plants for bacteria, fungi, or insects, as well as conserving soil moisture, as has been noted previously by Núñez-Elisea et al. (2005). It also warmed the soil earlier in spring, and may have served as a barrier to soil-emerging insects such as cherry fruit fly or japanese beetle. Of particular interest is that early in the season, when the soil might act as a heat sink for re-radiation of heat during frosty nights, the tunnel and the weed barrier promoted greater heat accumulation in the soil during the day. Observational data in 2006 indicated that the tunnel plots had less frost damage to cherry flowers compared with the unprotected plots when the covers were installed during bud swell.

When the tunnels were covered from bloom to harvest, rather than only during the final stages of fruit ripening, about $10 \%$ more growing degree-days (base $10{ }^{\circ} \mathrm{C}$ ) were accumulated (2007 data). The average wind speed generally was reduced by about $50 \%$ in the tunnels, and wind gust speeds recorded in the tunnels were 8 to $15 \mathrm{~km} \cdot \mathrm{h}^{-1}$ lower than outside. These factors probably were similar in 2006 and contributed to the differences in second-year tree development at SWMREC: the tunnel trees grew $\approx 24 \%$ taller but were $18 \%$ smaller in girth in 2006, although there were no differences in number (23) or in average length $(58 \mathrm{~cm})$ of lateral shoots formed. In 2007 , there was significantly more lateral growth on trees under the tunnels, most likely due to an early infection period for foliar diseases that caused premature leaf drop and terminal bud set on the unprotected trees. It appears that development of the fruit-bearing lateral system within the canopy will be $\approx 50 \%$ to $\approx 70 \%$ complete in 2008 (during which the entire canopy will approach complete filling of space), providing significant yield potential in the fourth season. While this is quite rapid for a typical sweet cherry orchard, it represents a substantial delay in production compared with vegetables and nonwoody berry crops.

The daily light integral recorded under the tunnels was about $26 \%$ lower than in full sunlight (as measured during the third season of use of the same plastic). This is comparable to a moderate level of shade, thereby altering the most sun-exposed leaves into moderately shaded leaves and, more importantly, altering midcanopy leaves that typically are moderately exposed to sun and shade into more heavily shaded leaves more similar to those deeper in the canopy of unprotected trees. This was evident from a $20 \%$ to $25 \%$ increase in average individual leaf area for trees in the tunnel, a classic leaf response to development in partial shade. The issue of shade was one factor for including the white reflective ground floor fabric in the tunnel system to increase the distribution of the reduced transmitted light by reflecting some of the light not intercepted by leaves back toward the canopy (data analysis was not complete at the time of this colloquium). Other climatic data from 2007, such as leaf wetness and relative humidity, are still being analyzed.

YIELDS, FRUIT QUALITY, AND RIPENING TIME. In 2005, the CHES tunnels were covered for only a few weeks before and during harvest, for rain protection. 'Rainier' fruit 

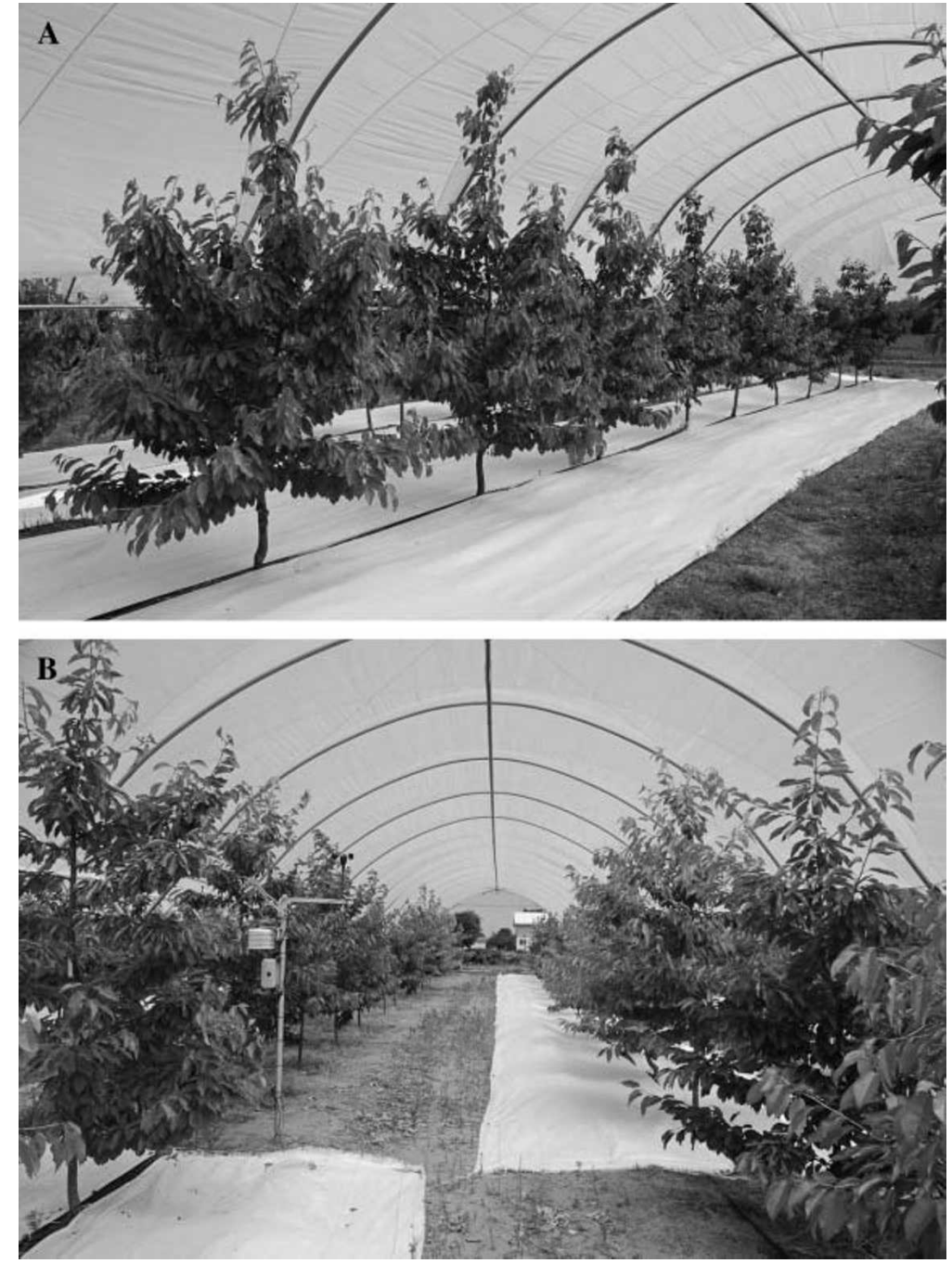

Fig. 1. (A) Sweet cherry trees trained to a single leader during the third growing season in the high tunnels at Michigan State University's Southwest Michigan Research and Extension Center (SWMREC) near Benton Harbor. Spacing is $2.0 \mathrm{~m}$ $(6.56 \mathrm{ft})$ between trees, $4.3 \mathrm{~m}(14.11 \mathrm{ft})$ between the two rows within the tunnel, and $1.5 \mathrm{~m}(4.92 \mathrm{ft})$ between the tree row and the side legs of the tunnel. (B) Note the location of the climatic monitoring station and the reflective ground floor fabric.

ripening was advanced in the tunnels, as determined by higher sugar levels in the fruit as well as larger fruit size. The only potentially damaging rain events occurred just before the covers were installed and just after harvest. Consequently, fruit quality was similar and excellent for tunnel and unprotected trees, being earlier for the tunnel trees. Fruit that ripened in the tunnel exhibited less windbruising than those in the unprotected plot.

In 2006 and 2007 at CHES, flowers not damaged by frosts or freezes tended to set very well, and the tunnels were covered from budswell through harvest in both years. However, 'Rainier' yields in 2006 to yields in the Pacific northwestern United States.

With regard to fruit quality, in 2006, the individual fruit weights from unprotected trees averaged $8.3 \mathrm{~g}$ for 'Rainier' / 'Gi 5' and $9.3 \mathrm{~g}$ for 'Rainier' /'Gi 6', whereas the tunnel-grown fruit averaged $12.5 \mathrm{~g}$ for 'Rainier' /'Gi 5' and 'Rainier' /'Gi 6'. Ripening was advanced in the tunnels, and the dramatically larger fruit size in the tunnels helped to offset the lower yields with respect to crop value. Sweet cherry fruit are sorted and graded for differential market value based on "row size" (i.e., the number of fruit needed to fit, side-byside, into a prescribed packing box 10.5 inches wide). The tunnel-grown 'Rainier'/ 'Gi 5' yield was $12.2 \mathrm{t} \cdot \mathrm{ha}^{-1}$ of $73 \%$ nine-row $(\approx 30 \mathrm{~mm}$ in diameter) and larger fruit, while the tunnel-grown 'Rainier' /'Gi 6' yield was $8.9 \mathrm{t} \cdot \mathrm{ha}^{-1}$ of $81 \%$ nine-row and larger fruit. In comparison, the distribution of fruit that was nine-row and larger from unprotected trees ranged from $3 \%$ for 'Rainier' /'Gi 5' to $9 \%$ for 'Rainier' /'Gi 6'. Accounting for premiums paid for larger fruit and labor costs for picking all fruit (whether large or small), crop value estimates revealed the most valuable production was for the moderate tonnage of large fruit on tunnel-grown 'Rainier'/'Gi 5', which was worth $\approx \$ 10,600 /$ ha more than the higher yield of smaller fruit outside the tunnel. Had there been any significant rain-cracking events in 2006, this gap in value would have been even greater due to cullage of unprotected fruit.

In 2007, the higher yields in the tunnels at CHES led to smaller fruit sizes compared with 2006. However, even though yields were similar between tunnel and unprotected trees, average fruit weights were still larger in the tunnels: 10.4 versus $9.9 \mathrm{~g}$ for 'Rainier' / 'Gi 5' and 11.2 versus $9.6 \mathrm{~g}$ for 'Rainier' / 'Gi 6' for tunnel versus unprotected trees, respectively. In 2006, the development of the red "blush" on the skin of the yellowfleshed 'Rainier' fruit (an important trait for premium markets) was markedly less for tunnel-grown fruit compared with unprotected fruit. The red pigment (anthocyanin) formation in the fruit skin is light dependent, and probably specifically dependent on the ultraviolet-A wavelengths (Zhou et al., 2007) that are partially screened 
out by polyethylenes that are ultraviolet stabilized. Therefore, in 2007 , the plastic was pushed up the sides of the tunnel arch ("venting") to a higher extent than in 2006; the white reflective ground fabric was installed to reflect more light back into the tree canopy, and the trees were pruned more strategically for better light distribution throughout the canopy. These measures successfully increased the amount of red blush development on fruit deeper in the canopy, increasing the percentage of blushed fruit that reached acceptable quality for premium markets.

In 2005 (tunnels were covered, without venting, only during Stage III of ripening) and 2006 (tunnels were covered, without venting, from budbreak through the end of summer), 'Rainier' fruit ripened (as determined by soluble solids concentration and stem pull force) several days earlier in the tunnels than on the adjacent unprotected trees. However, in 2007 (tunnels were covered, with venting for temperature and humidity moderation, from budbreak through the end of summer), the use of the white reflective ground fabric inside and outside the tunnel advanced ripening of the unprotected, fully sunlit trees to a greater extent than did the vented tunnels plus the fabric. Thus, cherry growers may be able to manipulate ripening by increasing air temperature (as with nonvented tunnels) or by increasing sunlight (as with orchard floor reflection), but reflection of the more limited light in a fully vented tunnel (hence, a reduced improvement in light and a minimal increase in temperature) may not advance ripening as much as orchard floor reflection under full sunlight conditions. Further research is underway to examine tunnel-covering plastics with different spectral transmittance properties, as well as earlyseason enclosure of tunnel sides and ends, as variables to further manipulate potential cherry ripening times.

INSECTS, DISEASES, AND BIRDS. In 2006 , the decision was made to use no synthetic insecticides or fungicides in the CHES tunnels or the comparison unprotected tree rows, to determine the impact of the tunnels on the incidence of potential insect pests and diseases. As noted above, the tunnel trees were covered at bud swell. Although the original plan was to remove the plastic after harvest, by late July, we noticed that the unprotected trees were severely infested by japanese beetle and infected with cherry leaf spot, while the tunnel trees had little to no evidence of damage from either pest (Fig. 2). In spite of the fact that japanese beetles are highly mobile and the open ends and sides of the tunnels presented no physical barrier to insect flight, apparently the imposition of $\approx 25 \%$ shade or the filtering of certain light wavelengths inhibited beetle movement into the tunnel. Therefore, the plastic covers were left on the tunnels until the beginning of October, when removal promoted the normal progression of leaf senescence and cold acclimation.

The healthier leaves late in the 2006 growing season on trees in the tunnels led to higher winter reserves, such as starch (J. Flore and L. Sage, unpublished data) and perhaps nitrogen. Interestingly, before the tunnels were covered in Spring 2007, an Arctic air mass brought record low temperatures during the first 2 weeks of April that resulted in significant freeze damage to flower and vegetative buds, as well as branches and even trunks of some cultivars. Freeze damage was much less in the tunnel trees, even though they were still uncovered, presumably due to the healthier foliage in 2006 and higher winter reserve levels.

Other insect pests that were less prevalent in the tunnels included plum curculio, which apparently did not move into the tunnels across pesticide-sprayed boundary trees
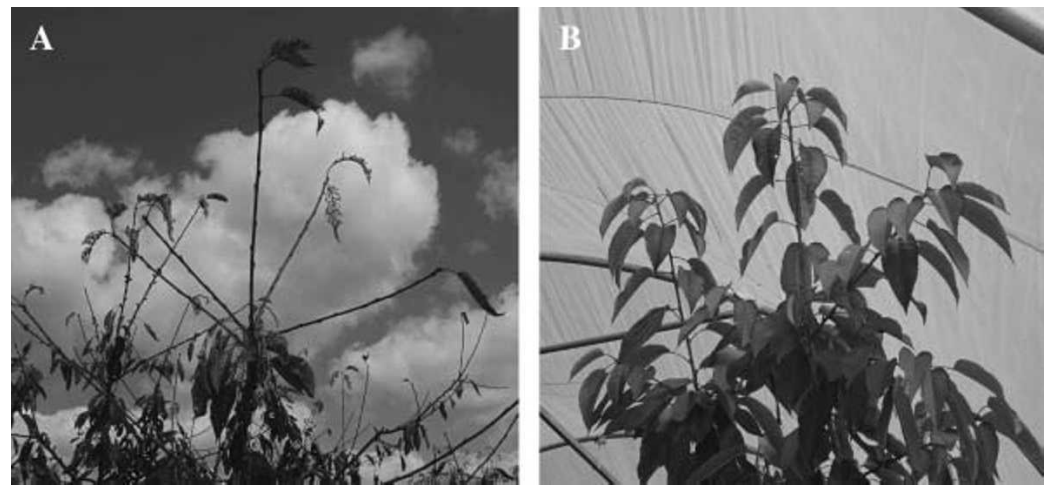

Fig. 2. Sweet cherry tree leaf damage and defoliation in Aug. 2006 due to cherry leaf spot and japanese beetle predation (A) outside the high tunnels and (B) inside the high tunnels (even with open ends and sides) as a consequence of differential leaf wetness for fungal spore germination and filtering of light wavelengths, which is apparently important for beetle flight and/or feeding activity. 
tunnel production if there are orchards nearby where it has already become established.

At CHES, the cultivars in the tunnels ripen midseason or later, and the tunnels are surrounded by numerous other sweet and sour cherry research orchards. Consequently, bird damage to fruit grown in these tunnels has been minimal in spite of the open tunnel ends and sides. Presumably, this is because a number of nearby cherry cultivars ripen outside the tunnels before those in the tunnel, and when the tunnel cherries are ripe, plenty of alternative food sources exist outside the tunnel. However, bird nests [primarily robins (Turdus migratorius)] have been found each year in tunnel-grown trees. At SWMREC, the tunnel orchards are isolated from other orchards and the cultivar mix includes a broad range of ripening times. Not surprisingly, bird damage in the first cropping year (2007) was extensive, requiring the installation of bird netting along the tunnel sides and ends. This was a fairly effective deterrent, and it allowed adequate air exchange to prevent the build-up of excessive heat and humidity under the tunnels, as well as the continued penetration of low-angle sunlight, unlike the microclimatic impacts that might be expected with the use of solid plastic or insectexclusion netting.

\section{Conclusions}

Multi-bay high tunnels appear to be a promising, albeit expensive, production technology for sweet cherries. High tunnel production for premium retail, pick-your-own, or farm markets is feasible and likely to be economically viable in the established fruitproducing areas of the Great Lakes states and provinces, and probably other temperate regions where sweet cherry trees will survive the winter. Potential advantages for orchard management include enhanced levels of protection from rain, spring frosts, certain insects such as japanese beetle, certain diseases such as cherry leaf spot, and birds when combined with side- and end-netting. Other advantages include the facilitation of customer or harvest crew picking of fruit even if it is raining, and earlier and more extensive vegetative growth to fill orchard space and hasten fruiting wood formation. Fruit quality can be superb in tunnel production systems, achieving large size, outstanding sugar levels, firm flesh texture, less wind bruising, and a superb glossy appearance. Yields can be excellent when honeybee pollination is supplemented with that of cultivated bumblebees or other native pollinators, but the tradeoff of yield versus fruit size must be managed strategically to optimize crop value for target premium markets. A complete economic evaluation of high tunnel production systems for sweet cherry remains premature, as the system management variables are numerous and certainly a number of them remain to be studied for optimization before input and output finances can be effectively determined.

Tree canopy management, particularly with respect to pruning for optimal distribution of the reduced light levels, is critical in high tunnels, particularly for blushed yellow cultivars like 'Rainier'. Planting and training systems that rapidly fill fruiting space within the cubic volume contained by the tunnel structure (while maximizing light interception and distribution) remain to be optimized. Irrigation is critical and drip irrigation is preferred to best manage humidity within the tunnels. If drip irrigation is installed, fertigation also may be necessary to deliver nutrients to the limited root zone, particularly in sandy soils. Synthetic pesticide use (and consequently input costs) can be reduced or eliminated dramatically, although under such conditions, some insect or disease pests may require vigilant monitoring (e.g., black cherry aphid, and brown rot). Further study of the promising impact of high tunnels on the potential for organic control of sweet cherry insects and diseases is needed.

\section{Literature cited}

Lamont, W.J. and M.D. Orzolek (eds.). 2003. High tunnel production manual. 2nd ed. Pennsylvania State University Center for Plasticulture, Rock Springs, PA.

Lamont, W.J., Jr., M.D. Orzolek, E.J. Holcomb, K. Demchak, E. Burkhart, L. White, and B. Dye. 2003. Production system for horticultural crops grown in the Penn State high tunnel. HortTechnology 13:358-362.

Lang, G. 2007. Timing critical to develop precocious sweet cherries. Fruit Grower News 46(2):12-15.

Lang, G.A. 2000. Precocious, dwarfing, and productive: How will new cherry rootstocks impact the sweet cherry industry? HortTechnology 10:719-725.

Lang, G.A. 2005. Underlying principles of high-density sweet cherry production. Acta Hort. 667:325-335.

Meland, M. 2005. Different technical designs for rain cover protection against cracking for sweet cherry orchards. Compact Fruit Tree 38(Spec. Ed.):31-35

Michigan State University. 2005a. MAWN: Michigan Automated Weather Network. 8 Apr. 2008. <http://www. agweather.geo.msu.edu/mawn/station. asp? $\mathrm{id}=\mathrm{clr}>$.

Michigan State University. 2005b. MAWN: Michigan Automated Weather Network. 8 Apr. 2008. <http://www. agweather.geo.msu.edu/mawn/station. asp?id=swm $>$.

Núñez-Elisea, R., H. Cahn, L. Caldeira, and C. Seavert. 2005. Synthetic fabric ground covers as a tool to promote early yields and fruit quality in Regina sweet cherry. Compact Fruit Tree 38(Spec. Ed.):38-39.

O'Rourke, D. 2006. World sweet cherry review: 2006 edition. Belrose Publications, Pullman, WA.

Pennell, D. and A.D. Webster. 1996. Sweet cherries: Protection of fruit from bird and rain damage, p. 393-407. In: A.D. Webster and N.E. Looney (eds.). Cherries: Crop physiology, production and uses. CAB International, Wallingford, UK.

Weaver, B. and M. Weaver. 2003. Under cover: High tunnels help expand u-pick sweet cherry season. Fruit Grower News $42(12): 1,9$.

Webster, A.D. and N.E. Looney. 1996. Cherries: Crop physiology, production and uses. CAB International, Wallingford, UK.

Zhou, B., Y. Li, Z. Xu, H. Yan, S. Homma, and S. Kawabata. 2007. Ultraviolet $A$-specific induction of anthocyanin biosynthesis in the swollen hypocotyls of turnip (Brassica rapa). J. Expt. Bot. 58: 1771-1781. 